\title{
Bibliographisches Abkürzungsverzeichnis
}

Die verwendeten bibliographischen Abkürzungen richten sich, soweit nicht anders angegeben, nach dem Abkürzungsverzeichnis des Reallexikons der Assyriologie (RIA).

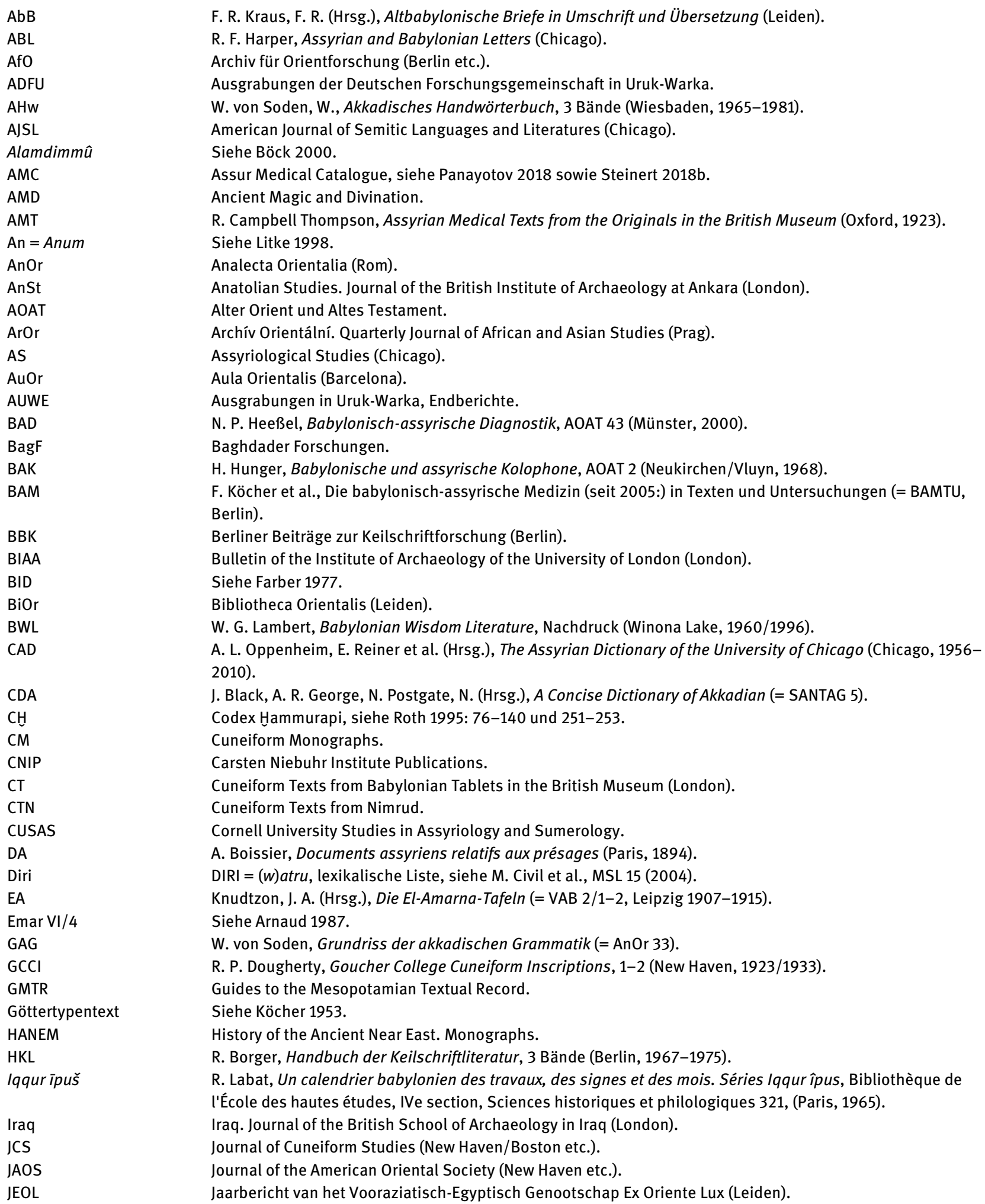




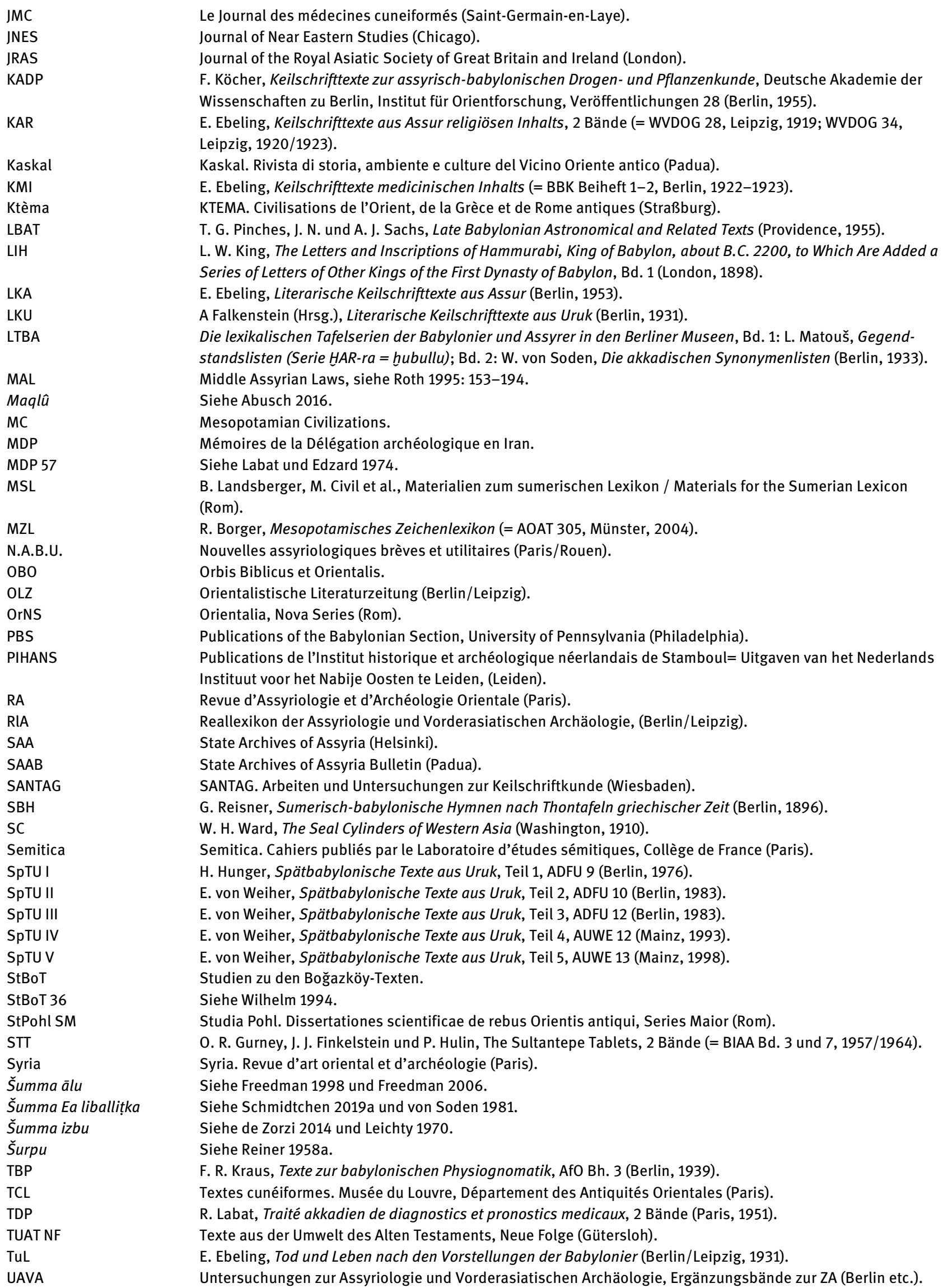


UET

UF

UGU.MU

Utukkū lemnūtu

$\mathrm{V} R$

VAB

WAW

WdO

WVDOG

YOS

ZA
Ur Excavations, Texts (London).

Ugarit-Forschungen. Internationales Jahrbuch für die Altertumskunde Syrien-Palästinas (Neukirchen-Vluyn). Siehe Couto Ferreira 2009.

Siehe Geller 2016.

H. C. Rawlinson (Hrsg.), The Cuneiform Inscriptions of Western Asia, Bd. 5: A Selection from the Miscellaneous Inscriptions of Assyria and Babylonia (London, 1909).

Vorderasiatische Bibliothek (Leipzig).

Society of Biblical Literature, Writings from the Ancient World Series (Atlanta).

Die Welt des Orients. Wissenschaftliche Beiträge zur Kunde des Morgenlandes (Wuppertal/Göttingen).

Wissenschaftliche Veröffentlichungen der Deutschen Orient-Gesellschaft (Leipzig/Berlin etc.).

Yale Oriental Series, Babylonian Texts (New Haven/London/Oxford).

Zeitschrift für Assyriologie und Vorderasiatische Archäologie (Leipzig etc.). 
